\title{
Research on the Connection relationship between Private Offering Fund and Share Price Index Futures
}

\author{
Fei Guo ${ }^{1}$, Li Zhou ${ }^{2}$, Hong Zhang ${ }^{2}$ \\ ${ }^{1}$ School of Economics,Beijing Wuzi University,Beijing,China \\ ${ }^{2}$ School of Information,Beijing Wuzi University,Beijing,China \\ Email:guofei9987@foxmail.com (Fei Guo)
}

Keywords: Private Offering Fund, Index, Granger causality test, Cointegration, VAR

\begin{abstract}
With the deepening of the reform of China's financial system, private offering funds have been becoming an important part of China's financial system, but there is little research on the index of private offering funds. This paper constructs an index, which covers $86.87 \%$ of the private funds for futures strategy, can better reflect the performance of those kinds of funds. Through Granger causality test, the IFLX1(a kind of share price index futures) is a factor that affects the performance of private offering funds in the short term, and in long term they are both factors to each other. The establishment of private offering fund performance index, is conducive to investors and regulatory authorities to further understand the status and history of the private sector. A scientifical private offering fund performance index does not exist at present, so this paper introduced the performance index of private offering funds to improve the financial indicators system.it has a strong theoretical and practical significance.
\end{abstract}

\section{Introduction}

With the 2014, large-scale development of private offering funds. By 2015, it continue to maintain the explosive growth. The number of Fund industry association has registered 9036, registered capitalreached 3.03 trillion yuan and capital paid-in reached 2.36 trillion yuan [1]. To establish a system of index for the private offering funds to scientifically evaluate the performance of China's private offering funds, has important theoretical and practical significance to the healthy and stable development of the fund industry and the whole financial industry as well as the investors' right decision [2].

At present, the similar research on the performance evaluation of the public fund is mainly about public offering funds, which is particularly relevant. The research on private offering funds, mainly focus on the micro level and individual analysis.There is little research on the index of private offering fund industry, while the private placement fund is becoming an important part of China's financial industry [3]. First, the financial index is an indicator of the state's macro financial situation. Second, it is conducive to the formulation and implementation of macroeconomic policies of the government. Third, it is conducive to private offering funds for self-evaluation. Fourth, it is conducive for investors to make decisions, help to make rational investment decisions, and finally make the whole financial industry rational.

Based on the above knowledge, we propose a set of index system which can reflect the performance of China's private offering fund, which is based on the net value of the private funds [4]. With the PMI index can reflect the trend of economic change, the index can macroscopically and dynamically reflect the overall situation of China's private offering fund [5]. 


\section{Basic principles organization of private funds index}

\section{About some realities.}

There are different regulatory agencies who have different regulations or policies. Legal about private offering fund information disclosure requirements are scattered in a number of laws and regulations.Disclosure standards are not uniform and comparability and operability is not strong. A scientifical index solves this problem.

Organization of the private offering fund performance index for futures strategy (we call it ppfi in this article).

We get the data from various private offering fund company website, "simuwang.com" and "howbuy.com". We get totally 17700 funds net data, 14852 of which are running and 2848 of which has been suspended. The data covers 98.19\% of China private fund. These funds, in accordance with its investment scope of classification, 9889 of them are "stock strategy", 2555 of them are "bond strategy", 959 of them are "futures strategy", 415 of them are "fund portfolio", and 3882 of them are "comprehensive management or others". In accordance with its investment way classification, 9451 of them are "stock bull", 131 of them are "Stock straddle", 116 of them are "quantify equity", 56 of them are" day trading ", 415 of them are " composite strategy ", 691 of them are "private placement" and 6840 of them are " other methods ".

\section{Calculation of index}

There are 959 "futures strategy", which covers more than $90 \%$ of those kind in China, we find that some of this private offering fund net data has the following characteristics:

1. Private offering fund net data disclosure time is not fixed. Their disclosure time is random and not uniform [6]. 2. The disclosure of the historical value interval is too large. Private offering funds, which has not this two characteristics, will be called "more complete disclosure of information fund" in this paper[7].

In view of the fact that mentioned above, we eliminate those "incomplete disclosure of information fund", and get 867 "more complete disclosure of information fund". We get the quantity of those funds:

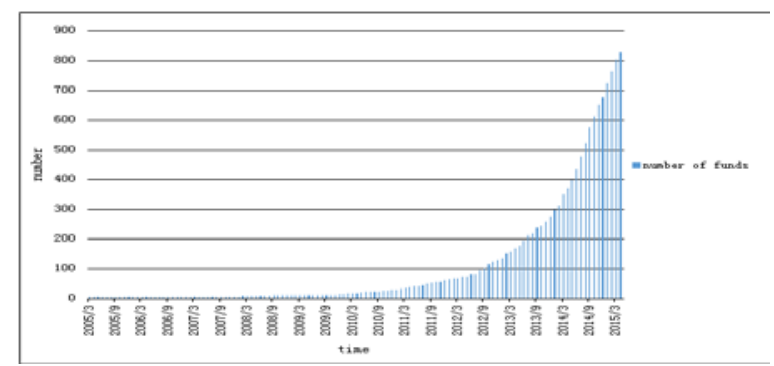

Fig 1.numbers of more complete disclosure of information fund

It can be found in figure 1, that, before March 2013, the "more complete disclosure of information fund" was growing slowly, but after March 2013, the "more complete disclosure of information fund" was growing fast. Therefore, we can choose March 2013 as the base period.

In this paper, we choose March 18, 2013 as the basic period and set the index of that day 1000.

The calculation of the base period.

In March 18, 2013, there was 157 “more complete disclosure of information fund”, we make an arithmetic weighted average and multiply a factor $(\delta(t))$ so the index in March 18, 2013 is 1000.

$$
\operatorname{ppfi}(t)=\delta(t) * \frac{\sum_{i=1}^{n_{t}} P_{i}(t)}{n_{t}},
$$

Where, $t=1, n_{t}=867$

\section{Time series variation of the ppfi}

Assume that there is no new fund to join in the $t+1$ day, and there is no fund to suspend in the $t+1$ day, then 


$$
\begin{array}{r}
\delta(t+1)=\delta(t) \\
p p f i(t+1)=\delta(t+1) * \frac{\sum_{i=1}^{n_{t+1}} P_{i}(t+1)}{n_{t+1}}
\end{array}
$$

Assume that there is new fund to join in the $t+1$ day, or there is fund to suspend in the $t+1$ day. We do the following in order to smooth the index in $\mathrm{t}+1$ day:

$$
\left\{\begin{array}{c}
p p f i(t+1)=\delta(t+1) * \frac{\sum_{i=1}^{n_{t+1}} P_{i}(t+1)}{n_{t+1}} \\
p p f i(t+1)=\delta(t) * \frac{\sum_{i=1}^{n_{t}} P_{i}(t+1)}{n_{t}}
\end{array} .\right.
$$

Deformation the formula (4):

$$
\delta(t+1)=\delta(t) * \frac{\sum_{i=1}^{n_{t}} P_{i}(t+1)}{\sum_{i=1}^{n_{t+1}} P_{i}(t+1)} * \frac{n_{t+1}}{n_{t}} .
$$

\section{The Interpolation of the net fund data.}

Though we have already obtained all the data of "the private offering fund performance index", the data is not all corresponding. It is necessary to use interpolation method. The daily net value of each fund is calculated by interpolation. In this paper, we take the three spline interpolation.

The calculation results.

The result is as figure 2

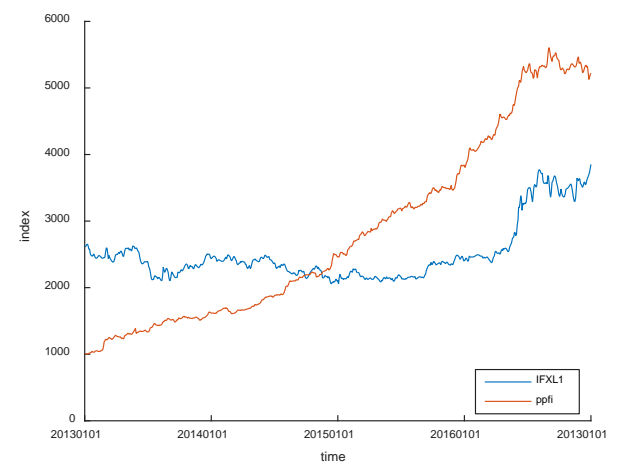

Fig 2.ppfi and IFLX1

Observe figure 2, you can directly get the following conclusions intuitively:

1) When the IFLX1 is stable, and the volatility is not obvious, the performance of private offering funds for futures strategy can maintain a good performance

2) When IFLX1 fluctuate, the performance of private offering funds for futures strategy is moderate.

3) In the bull markets, there is an obvious time lag between ppei and IFLX1.

\section{Statistical analysis of ppfi}

Suppose there are regression relation between $p p f i$ and shci, the regression relationship cannot be obtained directly by the least square method. We need to verify whether there is a long-term equilibrium relationship firstly. In order to do that, Cointegration should be done with ppfi and IFLX1.

\section{Stationary test of variable.}

The Stationary test of variable time series of the stability of a sequence of mean, variance and covariance is stable. If the mean, variance and covariance of a time series are not changed with time, and the order of the sequence is related to the order of time delay, we call the time series is 
stationary. Generally speaking, when the time series is not stable, it will lead to the phenomenon of "false regression" and the statistical test is meaningless. Therefore, in order to determine the stability of the sequence, the variable must be tested before the cointegration test is conducted.

Do ADF test toppfi, shci and their first difference. The outcome of the test is as follows:

Table 1. ADF test

PARAMETER

\begin{tabular}{c|cccc}
\hline \multirow{2}{*}{ ppfi } & t-Statistic & 1.5530 & -0.2926 & 1.8586 \\
& Prob & 0.9994 & 0.9908 & 0.9852 \\
IFLX1 & t-Statistic & $p p f i 0.6695$ & -0.7336 & 1.2212 \\
& Prob & 0.9915 & 0.9695 & 0.9436 \\
D( ppfi $)$ & t-Statistic & -9.8045 & -10.2595 & -9.6587 \\
& Prob & 0.0000 & 0.0000 & 0.0000 \\
D(IFLX1) & t-Statistic & -17.5268 & -17.7417 & -17.4879 \\
& Prob & 0.0000 & 0.0000 & 0.0000 \\
\hline
\end{tabular}

According to the table 1, the variable ppfi, IFLX1 is not stable, but their first difference is stable. The statistical variables $t, \mathrm{~F}, \mathrm{R}^{2}$ that are obtained by OLS regression are invalid. Due to the stability of the first difference of ppfi , IFLX1, there is long term equilibrium relationship.

\section{Granger Causality Tests.}

Granger causality test is proposed by Granger (1969).It is causality test method to analyze problems [8]. Based on the system of vector auto regression (VAR), it is assumed that the prediction information of each variable is contained in the time series of these variables [9]. In order to explain the formulation of the method, the following two variables will be used, inspection requirements for the estimation of the following regression:

$$
\left\{\begin{array}{l}
\operatorname{IFLX} 1_{t}=\partial_{1}+\sum_{i=1}^{n} \gamma_{i} I F L X 1_{t-i}+\sum_{j=1}^{n} \lambda_{i} p p f i_{t-j}+\varepsilon_{1 t} \\
\text { ppfi }_{t}=\partial_{2}+\sum_{i=1}^{m} \varphi_{i} I F L X 1_{t-i}+\sum_{j=1}^{m} \phi_{i} p p f i_{t-j}+\varepsilon_{2 t}
\end{array}\right.
$$

If accept. $H_{01}: \lambda_{1}=\lambda_{2}=\ldots=\lambda_{n}=0$., ppfi $i_{t}$ is not the Granger cause of .IFLX $1_{t} .$. otherwise, $p p f i_{t}$ is the Granger cause of IFLX $1_{t}$.If accept $H_{02}: \varphi_{1}=\varphi_{2}=\ldots=\varphi_{n}=0, I F L X 1_{t}$ is not the Granger cause of ppfi $i_{t}$. Otherwise, IFLX $1_{t}$ is the Granger cause of $p p f i_{t}[10]$.

The first difference of ppfi, shci are stable. Thus Granger causality test can be done to d ( $p p f i$ ), $\mathrm{d}$ ( IFLX1). The outcome of the Granger causality test is as follows (table 2)

Table 2 .Granger causality test of shci,ppfi and their 1st difference

\section{GRANGER CAUSALITY TEST}

\begin{tabular}{|c|c|c|c|c|}
\hline \multirow[t]{2}{*}{ LAG } & Null Hypothsis & F-tatistics & Prob & Conclusion \\
\hline & $\mathrm{d}(\mathrm{IFLX} 1)$ does not Granger cause $\mathrm{d}(p p f i)$ & 64.4675 & 4.E-15 & Reject \\
\hline \multirow[t]{2}{*}{1} & $\mathrm{~d}(p p f i)$ does not Granger cause d(IFLX1) & 1.61204 & 0.2046 & Accept \\
\hline & d(IFLX1) does not Granger cause d( ppfi $)$ & 9.53778 & 2.E-11 & Reject \\
\hline \multirow[t]{2}{*}{7} & $\mathrm{~d}(p p f i)$ does not Granger cause d(IFLX1) & 1.70135 & 0.1055 & Accept \\
\hline & d(IFLX1) does not Granger cause d( ppfi ) & 9.01934 & 8.E-12 & Reject \\
\hline 8 & $\mathrm{~d}($ ppfi $)$ does not Granger cause d(IFLX1) & 2.28879 & 0.0201 & Reject \\
\hline
\end{tabular}


At a significant level of 0.05 , When the lag is 1,the change of the private offering fund performance index for futures strategy does not the Granger cause the change of IFLX1 ,and the change of IFLX1 dose Granger cause the change of private offering fund performance index. When the lag is 7 , it is still the same. When the lag is 8 , the change of the private offering fund performance index and the IFLX1 does mutually Granger cause.

Johansen cointegration test and VAR model.

We use Johansen cointegration test method to test the cointegration, which is based on the VAR model. Consider the following P order VAR model:

$$
\begin{aligned}
p p f i_{t}= & A_{1} * p p f i_{t-1}+A_{2} * p p f i_{t-2}+\ldots \\
& +A_{p} * p p f i_{t-p}+B_{0} I F L X 1+\varepsilon_{t}
\end{aligned}
$$

$p p f i$ is not stable,if there is cointegration between ppfi and shci, we can draw conclusions. The explanatory variables ppfi and the explanatory variables shci have long-term equilibrium relationship.

Equation (7) can be written as follows:

$$
\Delta I F L X 1_{t}=\beta_{0}+\beta_{1}^{*} \Delta p p f i_{t}+\left(\beta_{2}-1\right) * e c m_{t-1}
$$

where, ecm t-1 $_{1}=I F L X 1_{t-1}-\frac{\beta_{1}+\beta_{3}}{1-\beta_{2}} * p p f i_{t-1}$. Its representation error correction term

We already know that ppfi, IFLX1 are not stable. We use Johansen cointegration test method with intercept and no trend in CE. The outcome is as follows (table 3):

Table 3. Johansen cointegration

TRACE STATISTIC TEST

MAX-EIGEN STATISTIC TEST

\begin{tabular}{c|cccc}
\hline $\begin{array}{c}\text { HYPOTHESIZED } \\
\text { NO. OF CE(S) }\end{array}$ & $\begin{array}{c}\text { Trace } \\
\text { Statistic }\end{array}$ & Prob & Max-Eigen Statistic & Prob \\
NONE & 16.86760 & 0.0309 & 12.82047 & 0.0835 \\
AT MOST 1 & 4.047121 & 0.0442 & 4.047121 & 0.0442
\end{tabular}

Table 4 .Maximum of the log likelihood values of the cointegration relationship UNRESTRICTED $\mid$ UNRESTRICTED

\begin{tabular}{|c|c|c|c|c|c|}
\hline \multicolumn{2}{|c|}{ COEFFICIENTS } & \multicolumn{2}{|c|}{ COEFFICIENTS (ALPHA) } & \multicolumn{2}{|c|}{ CUEFFICIEIVIS } \\
\hline ppfi & IFLX 1 & $\mathrm{D}(p p f i)$ & IFLX 1 & $\mathrm{D} 2(p p f i)$ & $\mathrm{D} 2($ IFLX1) \\
\hline 0.001018 & -0.002572 & 1.489602 & 3.322910 & -0.003832 & -0.008547 \\
\hline 0.000122 & 0.002060 & -1.286651 & 1.180006 & (0.00198) & $(0.00284)$ \\
\hline
\end{tabular}
COINTEGRATING COEFFICIENTS

Prob of the two method are all less than 0.05. Reject the original hypothesis and there is a cointegration relationship between $p p f i$ and shci.Join a regularization constraint, this constraint is

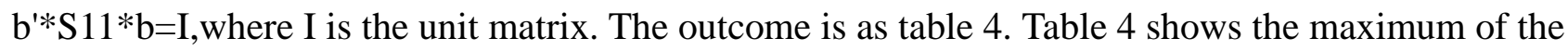
log likelihood values of the cointegration relationship, the relationship is also the regression of the VAR regression model. This form can be written as $\left(\right.$ ppei $_{t}-$ ppei $\left._{t-1}\right)-0.6484 * d(I F L X 1)=\tilde{u}$, and there is a positive correlation between ppfi and IFLX1the long-term equilibrium, the change of IFLX1 rose $1 \%$ per share, the change of private offering fund performance index for futures strategy will rise by $0.6484 \%$.

After the cointegration relationship is obtained from the Johansen cointegration test, the error correction term can be used to construct the error correction term and the VAR model, which is used as the regression variable. Considering the AIC information criterion and the SC criterion, the most appropriate delay is 1, 2, and 3. The outcome results of the VAR model with 3 order lags are table 5 
Table 5. VAR model estimated coefficient

\begin{tabular}{|c|c|c|c|c|c|}
\hline & ppfi (-1) & $p p f i \quad(-2)$ & ppfi (-3) & C & IFLX 1 \\
\hline \multirow{3}{*}{$p p f i$} & 1.436036 & -0.610167 & 0.175479 & 10.65679 & -0.004059 \\
\hline & $(0.03667)$ & $(0.06078)$ & (0.03683) & (5.13861) & $(0.00255)$ \\
\hline & [ 39.1622] & {$[-10.0384]$} & [ 4.76469] & [ 2.07386] & {$[-1.59013]$} \\
\hline
\end{tabular}

Write the VAR model of the estimated results:

ppfi $_{t}=1.4326 *$ ppfi $_{t-1}-0.6091 *$ ppfi $_{t-2}-$

$0.1789 * p p i_{t-3}-0.008879 *$ IFLX $1+$

$18.1155+\tilde{\varepsilon}$

VAR test of the residual figure is as follows:
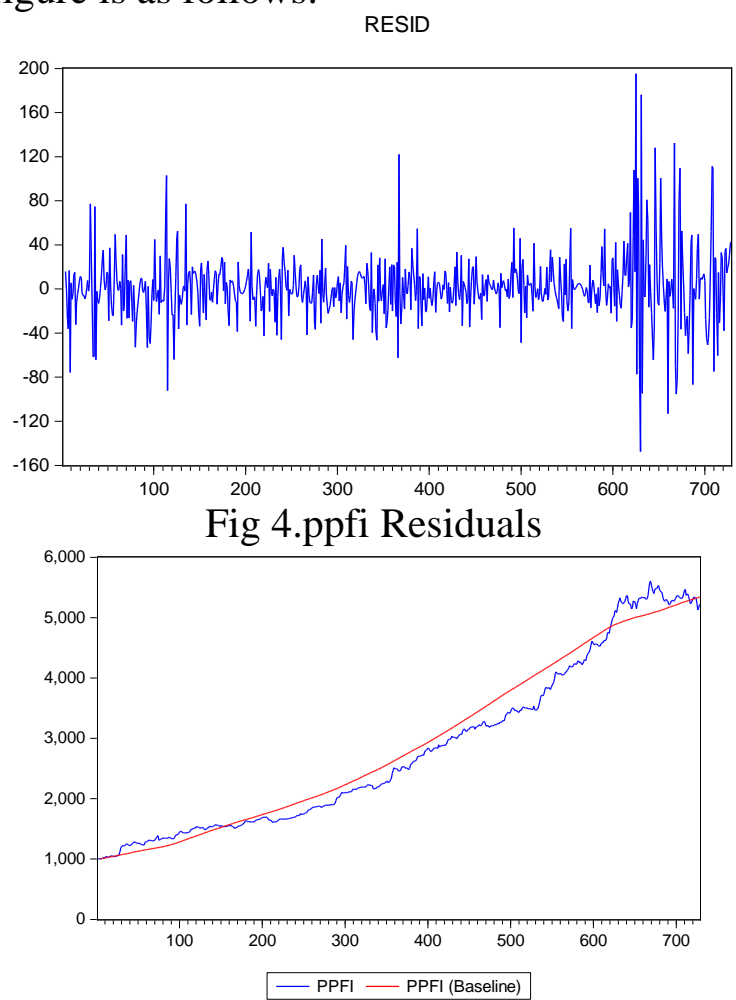

Fig 5. ppfi Predictive value

Using the sequence of each predictive value for the iterative calculation, we can output dynamic simulation results of the private offering fund performance index, as shown in figure 4

\section{Conclusion}

We organized the private offering fund performance index. Through the statistical analysis, we find that the performance of Chinese private offering funds and the IFLX 1 has the following relationship.1)in the short term, the IFLX1 is a factor that affects the performance of private offering funds.In the long term, the two are mutually affected)there is a positive correlation between the private performance and the IFLX1.

The establishment of private offering fund performance index is conducive to investors and regulators to understand the situation and history of the private fund industry. The current private offering fund performance index does not exist, so this paper introduced the performance index of private funds to improve the financial indicators system, with a strong theoretical and practical significance.

\section{Acknowledgements}

This paper is supported by the project "Model and Algorithm Research on congestion of picking up system in distribution center”(0541502703);Funding project for Beijing Wuzi University, Yunhe scholars program(00610303/007). 


\section{Reference}

[1] China Securities Investment Fund Industry Association. Private registration report [R](vol. 3).2015(6)

[2] Jiamin Tian, “The present situation and development of private offering funds in China” [J]. Modern Business, vol.20 , PP. 166-167 , 2015

[3] Qiqi Wang,"Problems and Countermeasures of the development of Inclusive Finance in China”[J]. Macroeconomic Management, vol.07, PP. 55-56 2015

[4] Xiaoxiang,"Study on the establishment of the financial index of Inclusive Finance” [J]. Wuhan Finance, vol. 09,PP. 7-11,2014

[5] Liu Mandan, "An empirical analysis of the relationship between private investment and economic growth -- Based on Granger causality test” [J]. Journal of Changchun University of Science and Technology(Social Sciences Edition), vol.05,PP. 62-65,2015

[6] LU Jing, “A theoretical and Empirical Study on the relationship between financial development and economic growth: a co integration analysis based on the panel data of China" [J], Chinese Journal of Management Science,vol.20 No.1 PP176-184,2012

[7] Cao Yunbo,"A study of the impact of public market manipulation on stock price -- An Empirical Analysis Based on VAR model” [J], Economic Forum, vol.528, PP 89-94 ,2014

[8] Jia Xiyun,“Application and empirical analysis of VaR model in stock market risk analysis” [J], Chinese Journal of Management Science, vol.22,PP 336-341,2014

[9] ZENG Lijuan, "The application of random search variable method in lagged regression model” [J], Journal of Hangzhou Normal University(Natural Science Edition), vol.13 No.6 PP. 664668,2014

[10]Huang Jingsan,"Pseudo maximum likelihood estimation of GARCH model based on high frequency data” [J], vol.37 No.6 PP. 1005-1017,2014 